\title{
Factors promoting knowledge sharing \& knowledge creation in banking sector of Pakistan
}

\author{
Faisal Abbas $^{\mathrm{a}^{*}}$, Abdul Rasheed ${ }^{\mathrm{b}}$, Um-e-Habiba ${ }^{\mathrm{c}}$ and Imran Shahzad ${ }^{\mathrm{d}}$
}

${ }^{a}$ Department of Commerce, University of Central Punjab Lahore, Pakistan (Sargodha Campus)
${ }^{b}$ National University of Modern Languages, Islamabad (Lahore Campus)
${ }^{c}$ Mohammad Ali Jinnah University Islamabad
$\frac{{ }^{d} \text { University of Central Punjab Lahore, Pakistan (Sargodha Campus) }}{\text { C H R O N I C L E }}$ A B T R A C T

Article history:

Received October 9, 2012

Received in revised format

29 November 2012

Accepted 26 December 2012

Available online

December 312012

Keywords:

Knowledge Sharing

Knowledge Creation

Culture, Trust

Motivation

Socialization

\begin{abstract}
The purpose of this study is to investigate the factors promoting knowledge sharing and knowledge creation in banking sector of Pakistan. With the help of literature review, we identified most important factors in knowledge sharing and knowledge creation including organizational culture, trust, motivation, employee's attitude and socialization. The populations selected for analysis consist of (250) male and female employees of banking sector of Pakistan and response have been received from 225 respondents. The collection of data was a very difficult task and it has taken almost four months. The data were collected from the five cities of Pakistan including Islamabad, Faisalabad, Multan, Peshawar and Lahore. The results show that all the factors have significant impact on knowledge creation and Knowledge sharing. The findings of the study also show that these factors are necessary for the promotion of knowledge creation and knowledge sharing culture in an organization. The knowledge sharing and knowledge creation are the keys for the success of an organization. A firm or an organization can sustain its competitive edge in market with the help of Knowledge sharing and knowledge creation. The final results of this study conclude that socialization factor is at top, trust factor is at second and motivational factor is at third according to the respondents' point of view.
\end{abstract}

\section{Introduction}

The main aim of this study is to investigate important factors in the process of knowledge sharing and knowledge creation in banking industry of Pakistan. Today, most of the organizations are busy to sustain their competitive edge in their respective product market. This basic need increases the importance of the knowledge implementation in organizations. In all the issues of knowledge management, the knowledge creation and knowledge sharing hold primary importance. It's the $21^{\text {st }}$ century, most of the things are looking, and waiting to change their presence in somewhat different way, the process, which did this called new creation. In this study, the primary objective is to point 
out the factors, which are positively influencing the knowledge sharing and knowledge creation process in an organization. The term "Knowledge Sharing" means to share one's knowledge with others and this will be very beneficial for the organizations. The "Knowledge Creation" means to create something new that must be beneficial for the success of the organization. The process of sharing and creation of knowledge is interdependent to each other. The sharing of knowledge means to share one's existing knowledge with others, the others will observe people's exiting experience and will produce new knowledge, and this process has no end. There are so many factors, which are affecting this process including Organization Culture Factor (OCF), Trust Factor (TF), Motivational Factor (MF), Employee's Attitude Factor (EAF), and Socialization Factor (SF). These are the factors, which are responsible for the process of sharing and creation of knowledge in an organization. The process of sharing and creating knowledge requires the positive effects from the above mentioned factors. One of the major factors is called organizational culture that must be supportive for the sharing and creation of knowledge in an organization. According to Davenport and Prusak, (1999), Knowledge includes values, experiences, opinions and information of the professionals. Drucker (1999) explained the concept of transfer of knowledge in an organization among the employees to improve their value and add something in their experiences and to describe the organizational learning and knowledge creation process. Another researcher has presented his idea that organizations are not only knowledge storage units rather the organizations must have potential to improve specific ability to Knowledge creation process. With the help of knowledge sharing attitude of one employee, a valuable personal knowledge can be transferred to the other individuals of the organization and that provides help to the organization for its success (Lin, 2008; Youndt \& Subramaniam, 2005; Wang \& Wang, 2012; Tagliaventi et al., 2010; Chen et al., 2012).

The purposes and objectives of the study are

1) To investigate the factors that promote knowledge sharing and knowledge creation in the banking sector of Pakistan,

2) To find out the impact of factors on Knowledge sharing and knowledge creation in banking sector,

3) To provide the guidelines to banker for sustaining competitive edge with the help of knowledge sharing and knowledge creation,

4) To give an easy approach to new researchers while working in Knowledge Management domain.

\section{Literature review}

There are so many researchers who have conducted the researches on the same areas and they have found different results and summary of some of their works constitutes literature view.

\subsection{Knowledge Sharing}

There are various studies on knowledge sharing process. To understand the concept of knowledge sharing we have to select different definitions on knowledge sharing presented by different renowned researchers. Lin et al. (2009) defined the term knowledge sharing as "Knowledge sharing can be defined as a social interaction culture, involving the exchange of employee knowledge, experience, and skills through the whole department or organization." According to Harder (2008) "Knowledge sharing can be defined as the voluntary social process to transfer, absorb and reuse the existing knowledge in order to serve an organizational end." Sethumadhavan (2007) explained the term knowledge sharing as "It is a systematic process to create, acquire, synthesize, learn, share and use knowledge and experience to achieve organizational goal. This knowledge can be form employee's 
mind or stored in paper form in filing cabinets and/or stored in electronic form”. According to the Bircham-Connolly et al. (2005) "The process of capturing knowledge or moving it form a source unit or recipient unit". Argote and Ingram (2000) explained that "Knowledge sharing is the process through which one unit is affected by the experience or another. In this respect, a unit can be an individual, a group or an organization”. According to Senge (1997) the sharing of knowledge is not only to share the information with others it means to share your knowledge with other for their help. Hendrisks (1999) explained in his study about knowledge sharing that knowledge sharing could affect the outcome of knowledge creation. He also explained that knowledge sharing is process of communication. Cabrera and Cabrera (2002) pointed that organizational knowledge have two dimensions that degree of articulation and degree of aggregation. The degree of articulation can be categorizing in different ways. Another very popular researcher Polanyi (1962), differentiated knowledge into two types tacit knowledge and explicit knowledge, which refer to make the sense for transferring and communication of knowledge to others. Some researchers differentiated between codified and tacit knowledge (Cowan et al., 2000; Nonaka, 1994; Saviotti, 1998), for that which knowledge can be articulated and capture in books. The degree of aggregation is further divided into individual and collective type of knowledge that knowledge is held by person in his mind and is embedded in the interactions among team members (Boh, 2007).

\subsection{Knowledge Creation}

After making the clear sense of knowledge sharing, now we are required to develop the sense of knowledge creation. There are so many researchers who have explained the concept of knowledge creation in their studies with respect to the different sectors. Numerous popular researchers have explained that the process of knowledge creations is based on different knowledge sharing among employees. Wai and Jayasingam (2012) explained in their study about knowledge creation that knowledge sharing culture was found to positively influence knowledge creation. According to Michell and Boyle (2010), knowledge creation means "the generation, development, implementation, and exploitation of new ideas". According to Soo et al. (1999) the knowledge creation is considered as important role of learning and innovation for an organization success and survival in market. Von Krogh et al. (2000) explained in their study that the knowledge creation process consists on the following activities as sharing tacit knowledge, creating concepts, justifying concepts, building a prototype, and cross-leveling the knowledge. Baland and Tenkasi (1995) explained the knowledge creation as "The individual does not think in isolation and is not an autonomous origin of knowledge". Nonaka et al. (2000) said that knowledge is created through the interaction amongst individuals and their environment. The process of knowledge creation can be influenced by different barriers and enablers (Roth et al. 1999).

\section{Methodology}

We have studied different research articles on knowledge sharing and creation but we found that every researcher has used very difficult approach to manage the data for the interpretation of the results. To solve the above problem, we have used very simple methodology for this study. We have developed a questionnaire with the help of senior researchers and other experts. We have performed focused group interviews to supplement the data from the different officers among different banks from the various regions of the country including two provinces. In this study, we selected the public and private bank branches of the Pakistan for population. First, we have selected employees posted as Branch Managers, Operations Managers, Credit Managers, and Cashier. Second, we selected employees who have qualification of Bachelor in commerce (B.Com), Master in Commerce (M.COM), Master in Business Administration (MBA), Master in information technology. Third, we selected only those employees who have at least 4 years of job experiences and 28 years old or above for our analysis to improve the reliability and validity of the study. The questionnaire was sent to the 250 Male and Female banking sector respondent in different cities of the Pakistan including 
Islamabad, Faisalabad, Peshawar, Multan and Lahore. These are the representative cities of main population in Pakistan. Four cities are from the province of Punjab because $60 \%$ of the whole population of Pakistan lives in Punjab. These cities were selected to make the findings of this study generalizable to the whole Pakistan. 226 questionnaires were received back for analysis. The overall response was almost 90\% (225/250) where the male response was $80 \%$ (180/225) while female response was $20 \%(45 / 225)$.

\subsection{Variables selection}

The primary objective of this study is on how to select variables. It was really, very difficult to select the area that is positively affecting the knowledge sharing and knowledge creation in the banking industry of Pakistan. For this purpose, we have availed the services of the different researchers, experienced workers of the banking sector who are doing their jobs at higher level at present and those who have been retired from different banks. After collecting the feedback about the knowledge sharing and knowledge creation from different sources, we have selected the following variables for study.

\subsection{Independent Variables}

(1) Organizational Culture Factor (OCF)

(2) Trust Factor (TF)

(3) Motivational Factor (MF)

(4) Socialization Factor (SF)

(5) Employee’s Attitude Factor (EAF)

\subsection{Dependent Variables}

Knowledge Sharing and Knowledge Creation

\subsection{Data Information Results and Discussion}

Table 1

Demographic Data of Population

\begin{tabular}{cccccc}
\hline Job description & Number & Percentages & Education & Number & Percentages \\
\hline Branch Manager & 78 & 35 & M.COM & 45 & 20 \\
Operations Manager & 66 & 29 & MBA & 60 & 27 \\
Credit Manager & 44 & 20 & MIT & 30 & 13 \\
Cashier & 37 & 16 & B.COM & 90 & 40 \\
\hline Total & 225 & 100 & Total & 225 & 100 \\
\hline
\end{tabular}

Table 2

Demographic Data of Population

\begin{tabular}{ccccccccc}
\hline Gender & Number & Per (\%) & Age & Number & (\%) & Experience (Years) & Number & $(\%)$ \\
\hline Male & 180 & 80 & $25-30$ & 27 & 12 & 5 & 13 & 6 \\
Female & 45 & 20 & $31-35$ & 49 & 22 & 10 & 58 & 26 \\
Total & 225 & 100 & $36-40$ & 51 & 23 & 15 & 42 & 19 \\
& & & $41-45$ & 36 & 16 & 20 & 57 & 25 \\
& & & $46-50$ & 36 & 16 & 25 & 38 & 17 \\
& & & $51+$ & 26 & 11 & 30 & 17 & 7 \\
\hline
\end{tabular}


Table 1 represents the demographic data of population. The detail of job description respondent as Branch Manager (BM), Operational Manager (OM), Credit Manager (CM) and Cashier while Education of the respondent Master in Commerce (M.COM), Master in Business Administration(MBA), Master in information technology (MIT) and Bachelor in Commerce (B.COM).

Table 3

Statistics of respondent for questionnaire

\begin{tabular}{|c|c|c|c|c|c|c|c|}
\hline Variables & & Male & & & male & & Cum yes \\
\hline & Yes & No & Yes \% & Yes & No & Yes\% & $\%$ \\
\hline OCF & 108 & 72 & 60 & 36 & 9 & 80 & 70 \\
\hline $\mathrm{TF}$ & 144 & 36 & 80 & 40 & 5 & 88 & 84 \\
\hline MF & 126 & 54 & 40 & 37 & 8 & 82 & 76 \\
\hline SF & 162 & 18 & 90 & 31 & 14 & 69 & 79.5 \\
\hline EAT & 117 & 63 & 65 & 33 & 12 & 73 & 69 \\
\hline
\end{tabular}

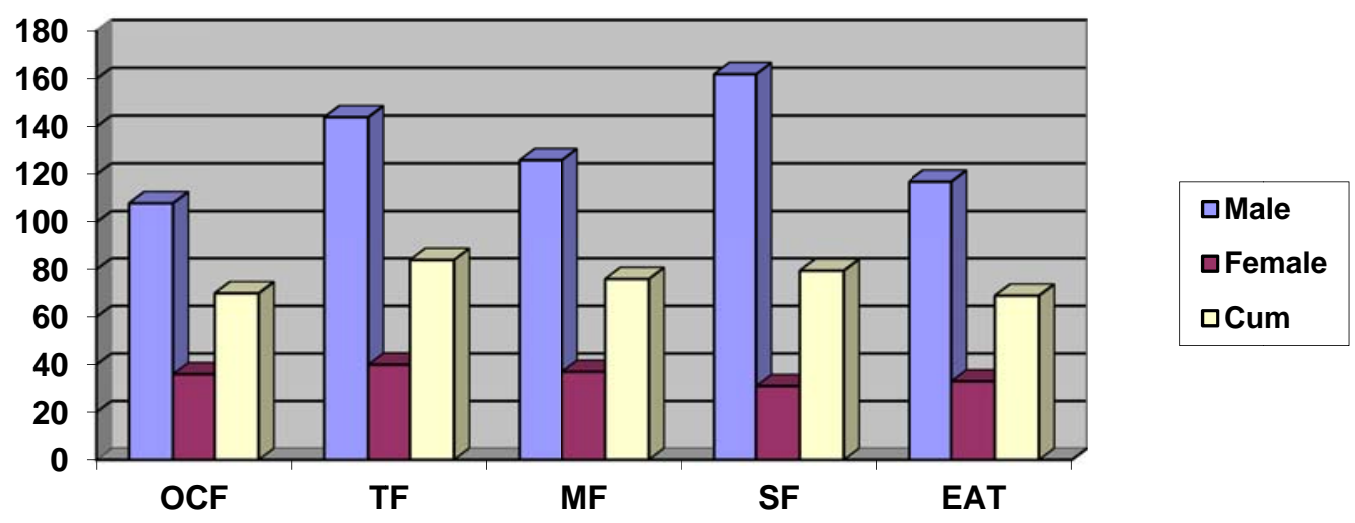

Fig. 1. The frequencies of OCF, TF, MF, SF and EAT

Fig. 1 shows statistics of organizational culture factor (OCF), trust factor (TF), motivational factor (MF), socialization factor (SF) and employee's attitude factor (EAT) and graphic bar represent that socialization factor is at top and trust at second and so on according to the results of the questionnaire response.

\section{Testing different hypotheses according to the response of respondents}

\subsection{Organizational Culture Factor (OCF) In Knowledge Sharing and Knowledge Creation}

$\mathrm{H}_{1}$ : Organizational Culture Factor has a positive impact on Knowledge Sharing and Knowledge Creation.

Govindarajan and Gupta (2000) and Gummer (1998) explained that an effective culture in banks is crucial in achieving effective knowledge sharing process. According to Abili et al. (2011), Yao et al. (2007) and Du et al. (2007) organizational culture is the shared value and belief and shapes the practice of the organizational members in the organizations and organizational culture affects the knowledge sharing process among employees. Organizational culture factor is the most important factor of the organizational knowledge sharing and knowledge creation. Organizational culture plays a very important role in the working of employees in an organization. Both Knowledge Sharing and Knowledge Creation are interdependent means knowledge sharing leads to knowledge creation. In 
other words, if there is no sharing then there is no creation. Organizational culture must be supportive and conducive for knowledge sharing and knowledge creation. A strong sense of support is needed for Knowledge Sharing and Knowledge Creation. According to the interviews of different higher level authorities of the banking it is found that the organization culture must be leaning and supportive and encouraging for employees. Organizational culture has both positive and negative effect on the environment of the organization. There must be friendly environment in organization for sharing and creation of knowledge. The organization culture must be attractive for the mitigation of gap between senior and junior for sharing their thoughts and creative ideas. According to different researchers Toh et al. (2003), Chong (2006) organizational culture is impacting the practice of knowledge management in an organization and they explained that knowledge sharing and knowledge creation are interdependent processes (Janz \& Prasarnphanich, 2003). If there is no sharing, there will be no creativity. In our study, the organizational culture positively influences all other factors such as trust, employees' attitude, motivational factor and socialization factor. The questionnaire was sent to the respondents and the responses received from them was as $60 \%$ of the male respondent 108 out of 180 have in the favoring of organizational culture and the female response was $80 \%$ (39 out 45 ).

\subsection{Trust Factor in Knowledge Sharing and Knowledge Creation}

$\mathrm{H}_{2}$ : Trust of employees has a positive impact on Knowledge Sharing and Knowledge Creation.

The concept of employees trust in management means that the organizational leaders will take such types of action, which will be beneficial for employees (Kim \& Mauborgne, 1997). According to Ford (2003) and Rolland and Chauvel (2000) the trust is often presented as one of the most important motivations for successful Knowledge sharing process. Trust is the medium through which knowledge can be shared smoothly and therefore the trust building is the key element at workplace to share the knowledge. Trust is another important variable of this study because the element of trust is important for both means for employees and for organization. Organization requires the trust of its employees for success and employees want the trust of organization for their jobs. The trust of employee is favorable for the working of the organization and that trust requires some few things to both some for employees and some for organization. Organization wants the trust in shape of commitment, loyalty of the employees and positive attitude of the employees. If the trust between organization and employees were good, that would be beneficial for sharing and creation of knowledge in an organization. According to the interviews of the different officers, trust is one the basic needs for both according to their wants. According to the questionnaire response for trust factor $80 \%$ male was positively responded (144 out of 180) while the response of female was $88 \%$ (40 out of 45).

\subsection{Motivational Factors in Knowledge Sharing and Knowledge Creation}

$\mathrm{H}_{3}$ : Motivational Factors has Positive impact on Knowledge Sharing and Knowledge Creation.

Bock et al. (2005) and Quigley et al. (2007) presented studies on motivational factor of employees. According to their opinions, motivational factors are of two types internal and external or material and nonmaterial, which are most effective in knowledge sharing process of the employees in an organization. There are different opinions about the motivation of the employees regarding their activities. Motivation is a basic need for work and if there is no motivation, there will be no interest. Without motivation, we cannot survive because it provides energy for work. It also has positive impact on the employees' sharing and knowledge creation in an organization. Motivation is another

factor of knowledge sharing and knowledge creation. Motivation has different direction so that it might be in form of encouragement or in shape of monetary reward to the employees. According to the response of the senior officers, one motivated employee has more potential to share his/her knowledge with other employees of the organization rather than unmotivated employee. According to 
the response of questionnaire for motivation, $70 \%$ from male member (126 out of 180) while 82\% was from female (37 out of 45).

\subsection{Employees' Attitude in Knowledge Sharing and Creation}

$\mathrm{H}_{4}$ : Employees’ Attitude has positive impact on Knowledge sharing and knowledge creation.

According to Szulanski (1996), the employees feel fear to share their unique knowledge due to the loss of their superiority in an organization. The behavior itself is identified as a degree to which an individual actually share his or her knowledge with others (Liang et al., 2008). The important variable of this study is employee's attitude. The attitude of employee plays a very important role in knowledge sharing and knowledge creation. There are so many factors, which are playing important role in employee's attitude such as job security, reward in shape of cash, organizational culture, working environment, motivation, work loan and leaders' behavior. If all these factors are supporting the employees then there would be positive attitude of the employee towards the knowledge sharing and knowledge creation. The findings of the study concluded that employee's positive attitude is basic need for knowledge sharing and knowledge creation. According to the questionnaire response about Socialization male was responded $90 \%$ in favor of socialization (162 out 180) while response from female was $69 \%$ (31 out of 45 ).

\subsection{Socialization in Knowledge Sharing and Knowledge Creation}

$\mathrm{H}_{5}$ : Socialization has positive impact on Knowledge Sharing and Knowledge Creation.

Socialization is the first phrase of SECI Model of Nonaka and Takeuchi (1995).They stated that socialization tacit knowledge was converted in the tacit knowledge by sharing experiences. The starting point for socialization was building the field of interaction that facilitates the sharing of experiences and mental models. One of the basic needs for everyone is to get respect and that requires your behavior towards others. If our behavior is good with others and we care about our employees regarding their needs and we are supporting the employees for their personal problems, then we expect good feedback from them. We are studying the knowledge sharing and knowledge creation in Pakistani banking sector in which most of the workers who're doing jobs are from same society. According to the different researchers, socialization is necessary for knowledge sharing and knowledge creation. If employees are not given importance then they will not be motivated towards the sharing of their tacit knowledge with other employees. According to questionnaire response about employees attitude from male was 65\% (117 out of 180) while 69\% was from female respondents.

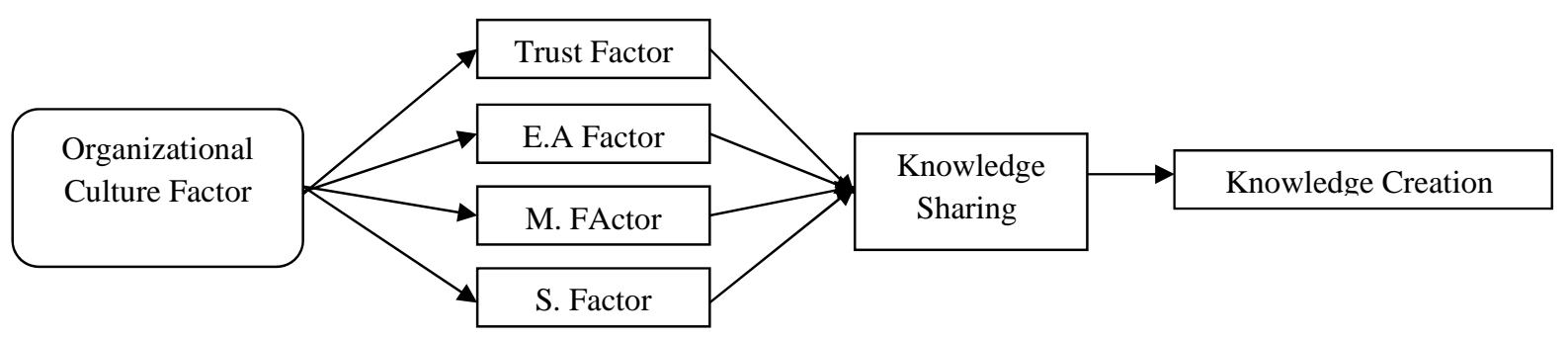

Fig. 2. Conceptual Framework of Knowledge Sharing and Knowledge Creation

We have prepared this model for the quick and effective understanding of this study. This model represents that organizational factor is affecting the all other factors of this study such as trust, employees' attitude factor, motivation factor, socialization that clearly mean to maintain such type of organizational culture, which supports all the factors attached with that for the betterment of organizational knowledge sharing and knowledge creation process. Knowledge sharing requires the 
positive relationship of the entire factor for better results and so on the knowledge creation requires positive response of the knowledge sharing process in an organization.

\section{Conclusions, recommendations and limitations}

The findings of any research article are deemed to be very important because they represent the final decision of the researchers about their studies. The primary objective of this study was to investigate the factors, which are promoting the knowledge sharing and knowledge creation process in banking industry of Pakistan. The factors used in this study had direct relationship with the dependent variables such as organization factor, trust factor, employee's attitude factor, motivation factor, and socialization factor. According to different previous studies' literature review, these all factors have positive affect on the employee's knowledge sharing and knowledge creation activities in an organization. According to our questionnaire response of the banking officers, there should be positive organizational culture in an organization for employees. Organizational culture affects the trust of employees, attitude of employees, motivation of employees, and socialization of employees in the process of knowledge sharing and knowledge creation process in an organization. From the results of this study, we have concluded that socialization factor is at top for knowledge sharing and knowledge creation in an organization while trust factor is the number second while motivation factor is in the third position and so on. The banking industry required to develop a positive relationship among all employees by considering the above mentioned factor, which could promote the knowledge sharing and knowledge creation process in an organization. The decision maker of this sector must capture this information for their success and for the improvement of banking sector performance. The new researchers must consider the other factor that can affect the knowledge sharing and creation process in an organization. The limitation of this research was data collection that is collected from the five cities of Pakistan due to the time constraint and cost effect and the rest of the cities are ignored. The response of the other cities may differ from the response of these cities from which the data were collected.

\section{References}

Abili, K., Thani, F. N., Mokhtarian, F., \& Rashidi, M. M. (2011). The role of effective Factors on Organisational Knowledge Sharing. Procedia-Social and Behavioral Science, 29, 1701-1706.

Argote, L., \& Ingram, P. (2000). Knowledge transfer: A basis for competitive advantage in firms. Organizational Behavior and Human Decision Processes, 82, 150-169

Bircham-Connoly, H., Corner, J., \& Bowden, S. (2005). An empirical study of the impact of question structure on recipient attitude during knowledge sharing. The Electronic Journal of Knowledge Management, 32, 1-10

Bock, G.-W., Lee, J.-N., \& Zmud, R. W. (2005). Behavioral intention formation in knowledge sharing. MIS Quarterly, 29(1), 87-111.

Boh, W.F. (2007). Mechanisms for sharing knowledge in project-based organization. Information and Organization, 17, 27-58.

Boland, R., \& Tenkasi, R. (1995). Perspective making and perspective taking in communities of knowing. Organization Science, 6(4), 350-372.

Cabrera, A., \& Cabrera, E. F. (2002). Knowledge-Sharing dilemmas. Organization Studies, 23(5), 687-710.

Chen, S.S., Chuang, Y.W., \& Chen, P.Y. (2012). Behavioral intention formation in Knowledge Sharing: Examining the roles of KMS quality, KMS self-efficacy, and Organizational climate, Knowledge-Based Systems, doi: 10.1016/j.knosy.2012.02.001.

Chong, S. C. (2006). KM Critical Success Factors: A Comparison of Perceived Importance Vs Implementation in Malaysian ICT Companies. The Learning Organization, 13(3), 230-256.

Cowan, R., David, P., \& Foray, D. (2000). The explicit economics of knowledge codification and tacitness. Industrial and Corporate Change, 9(2), 211-253. 
Davenport, T. H., \& Prusak, L. (1999). Working Knowledge: How Organization Manage What They Know. Boston: Harved Business School Press.

Drucker, P.F. (1999). Knowledge-Worker productivity: the biggest challenge. California Management Review, 41(2), 79-94.

Du, R., Ai, S., \& Ren, Y. (2007). Relationship between knowledge sharing and performance: A Survey in Xi' an, China. Expert Systems with Applications, 32, 38-46.

Ford,D.P. (2003). Trust and Knowledge management: The seeds of success. In: Handbook on Knowledge Management Holsapple Cw (ed), 553-576. Springer-Verlag, Berlin, Heidelberg.

Govindarajan, V., \& Gupta, A.K. (2000). Knowledge management's social dimension: Lesson from Nucor Steel. Sloan Management Review, 42, 87-105

Gummer, B. (1998). How do rewards and management styles influence the motivation to share knowledge? In: SMG Working Paper No. 6/2008

Harder, M. (2008). How do rewards and management styles influence the motivation to share knowledge? In: SMG Working paper No.6/2008

Hedrisks, P. (1997). Why Share Knowledge? The Influence of ICT on Motivation of Knowledge Sharing. Knowledge and Process Management. 6(2), 91-100.

Janz, B. D. \& Prasarnphanich, P. (2003). Understanding the antecedents of effective knowledge management: The importance of knowledge-centered Culture. Decision Science, 34(2), 351-384.

Kim, W. C., \& Mauborgne, R.A. (1997). Procedural justice, attitude, and subsidiary top management compliance with multinationals corporate strategic decisions. Academy of Management Journal, 36(3), 502-526.

Yi, L.W., \& Jayasingam, S. (2012). Factors driving knowledge creation among private sector organization: Empirical evidence from Malaysia. Journal of Organizational Knowledge Management. Article ID 199983.

Liang, T., P., Liu, C.-C., \& Wu, C.-H. (2008). Can social exchange theory explain individual knowledge-sharing behavior? A meta- analysis. In: ICIS 2008 Proceedings

Lin, H.-F., Lee, H.-S., \& Wang, D.W. (2009). Evaluation of factors influencing knowledge sharing based on a fuzzy AHP approach. Journal of Information Science, 36, 25-44.

Lin, W.-B. (2008). The Exploration factors of affecting knowledge sharing- the case of Taiwan's high-tech industry. Expert Systems with Application, 35(3), 661-676.

Mitchell, R. \& Boyle, B. (2010). Knowledge creation measurement methods. Journal of Knowledge Management, 14(1), 67-82.

Nonaka, I. (1994). A dynamic theory of organizational knowledge creation. Organization Science, 5(1), 14-37.

Nonaka, I., Toyama, R., \& Konno, N. (2000). SECI, Ba and Leadership: A unified model of dynamic knowledge creation. Long Range Planning, 33(1), 5-34.

Polanyi, M. (1962). Personal Knowledge: Toward a post-Critical philosophy. New York: Harper Torchbooks.

Quigley, N. R., Tesluk, P.E., Locke, E. A., \& Bartol, K.M. (2007). A Multilevel investigation of the motiviational mechanisms underlying knowledge sharing and performance. Organization Science, 18(1), 71-88.

Rolland, N., \& Chauvel, D. (2000). Knowledge transfer in strategic alliance, In: Knowledge Horizons: The Present and the Promise of Knowledge Management Despres C\& Chauvel D (Eds), pp.225-236. Buterworth Heinemann, Boston, MA

Roth, J., Floren, H. \& Ingelgard, A. (1999). Knowledge creation in the context of continuous improvements. Paper presented at EIASM in Cambridge. 1999.

Saviotti, P. P. (1998). On the dynamics of appropriability, of tacit and of codified knowledge. Research Policy, 26(7-8), 843-856.

Sethumadhavan, R. (2007). Importance of knowledge sharing for organizations.

Senge, P. (1997). Sharing Knowledge. Executive Excellence. 15, 11-12. 
Soo, C. W., Devinney, T. M., \& Midgley, D. F. (1999). The Process of Knowledge Creation in Organizations. Centre for Corprate Change; Australian Graduate School of Management; The University of New South Wales, Australia.

Subramainiam, M., \& Youndt, M. A. (2005). The influence of intellectual capital on the types of innovative capabilities. Academy of Management Review, 48, 450-463.

Szulanski, G. (1996). Exploring internal stickiness: impediments to the transfer of best practice within the firm. Strategic Management Journal, 17, 27-43.

Tagliavebti, M. R., Bertolotti, F., \& Macri, D.M. (2010). A perspective on practice in interunit knowledge sharing. European Management Journal, 17, 27-43.

Toh, H. H., Jantan, M. \& Ramayah, T. (2003). Knowledge management: An exploratory study on Malaysian organization. The International Journal of Knowledge, Culture and Change Management, 3, 995-1014.

Von Krogh, G., Ichijo, K., \& Nonaka, I. (2000). Enabling Knowledge Creation: how to unlock the mystery of tacit knowledge and release the power of innovation. Oxford University Press, Us.

Wang, Z., \& Wang, N. (2012). Knowledge sharing, innovation and firm performance. Expert Systems with Applications, 39, 8899-8908.

Yao, L.J., Kam, T.H.Y., \& Chan, S.H. (2007). Knowledge sharing in Asian public administration sector: the case of Hong Kong. Journal of Enterprise Information Management, 20(1), 51-69. 